\title{
Hearts not dead after circulatory death
}

\author{
Hendrik T. Tevaearai Stahel ${ }^{1}$, Andreas Zuckermann ${ }^{2}$, Thierry P. Carrel ${ }^{1}$ and \\ Sarah L. Longnus ${ }^{1 *}$ \\ ${ }^{1}$ Clinic for Cardiovascular Surgery, Bern University Hospital (Inselspital), University of Bern, Bern, Switzerland, ${ }^{2}$ Department of \\ Cardiac Surgery, Medical University of Vienna, Vienna, Austria
}

Keywords: heart transplantation, DCD heart transplantation, DCD cardiac graft, dconation after circulatory death, marginal heart donors, non-heart beating donors

In recent weeks, two pioneering cardiac surgery teams, Dhital and colleagues in Australia (1) and Large and colleagues in the UK (2), reported on what could rapidly become the best and sole affordable solution to the relentlessly growing number of patients awaiting heart transplantation, i.e., transplantation of grafts obtained from donors after death following circulatory arrest, previously termed "non-heart beating donors." Both groups presented their slightly differing approaches to organ procurement and evaluation at the 2015 Annual Meeting of The International Society for Heart \& Lung Transplantation, confirming several successful short-term outcomes for adult, orthotopic heart transplantation with donation after circulatory death (DCD).

As would be expected, a handful of specialists from around the world enthusiastically recognize a

OPEN ACCESS

Edited by:

Massimo Bonacchi,

Università degli Studi di Firenze, Italy

Reviewed by:

Gabriella Di Lascio,

Azienda Ospedaliero Universitaria

Careggi, Italy

Roberto Corti,

Herzklinik Hirslanden, Switzerland

*Correspondence:

Sarah L. Longnus sarah.longnus@insel.ch

Specialty section:

This article was submitted to Heart Surgery, a section of the journal

Frontiers in Surgery

Received: 22 June 2015

Accepted: 30 August 2015

Published: 14 September 2015

Citation:

Tevaearai Stahel HT, Zuckermann A,

Carrel TP and Longnus SL (2015)

Hearts not dead after

circulatory death.

Front. Surg. 2:46.

doi: 10.3389/fsurg.2015.00046 realistic complement to "traditional" cardiac donation after brain death (DBD), whereas others may condemn this approach, considering the ethical, practical, and liability aspects as indomitable. Many remain uncertain, possibly because of the apparent paradox, or at least the uncertainty, surrounding transplantation of hearts obtained from donors after "cardiac death." The Times recently titled “"dead» hearts successfully transplanted into living patients" $(2,3)$. When it comes to DCD hearts, it appears inappropriate to speak of donation after cardiac death, and potentially even misleading, given that hearts are able to withstand limited periods of warm ischemia without cardioprotection. Although in some countries determination of death based on cardiocirculatory criteria alone is permitted, in many, a prolonged waiting period (e.g., 10-20 min) between circulatory arrest and organ procurement is required to ensure that permanent neurologic damage has occurred $(4,5)$. A better terminology (6) would therefore be "DCD."

One important aspect of these reports lies in the fact that this approach goes against the established dogma that irreversible lesions immediately follow the onset of myocardial ischemia. Indeed, the very first heart transplantations, including those performed by Barnard in 1967, were performed with DCD organs (7). However, with the establishment of brain death criteria in the 1970s, DCD hearts were considered "substandard" and therefore rapidly abandoned. More recently, with revival of interest in DCD donation for improving graft availability notably for kidney, liver, and lung, five categories of DCD patients have been established in the modified Maastricht classification system (8). Distinctions between the different categories are based on the specific circumstances surrounding donor death; for example, dead on arrival at the hospital versus anticipated circulatory arrest following withdrawal of treatment. Furthermore, types of DCD patients have also been classified as controlled or uncontrolled according to whether or not the precise course of circulatory death is known. In theory, all DCD patients are potential heart donors, provided that the inclusion criteria are met and ischemic time is limited; however, it is currently unclear whether certain DCD categories would produce better outcomes. It could be argued, for example, that Maastricht category III donors (anticipated circulatory arrest) would be best suited for cardiac graft donation as conditions are controlled and pre-circulatory arrest 
interventions to limit heart damage may be possible. Yet these donors may undergo asphyxiation, and are therefore expected to experience pressure and volume overload both in the left and right ventricles, possibly leading to cardiac damage (9). This is in contrast to DCD donors who experience circulatory arrest subsequent to exsanguination; in which no overload-related damage, and thereby improved recovery, is expected (10); however, in this case circulatory arrest cannot be anticipated and pre-ischemic cardioprotective interventions are impossible. In addition to graft quality considerations, legal requirements may influence the use of specific DCD donor categories for heart transplantation.

Importantly, all potential DCD grafts undergo unavoidable warm ischemia before cold preservation solutions can be instilled. Notably, the warm ischemic times reported by Dhital for three of their cases ranged between 22 and $28 \mathrm{~min}$, in agreement with previous pediatric DCD heart transplantations (11) and multiple pre-clinical studies demonstrating myocardial warm ischemic tolerance of almost $30 \mathrm{~min}$. Therefore, a window of opportunity remains to protect, harvest, and evaluate the heart. The real challenge of DCD heart transplantation is thus to take advantage of this limited opportunity to counteract risks related to injury resulting from the inevitable ischemia and subsequent reperfusion.

Now these recent reports of DCD heart transplantation are not simply arbitrary provocations, but rather the result of mature, albeit somewhat differing, strategies. Providing that the warm ischemic time was $<30 \mathrm{~min}$, Dhital and colleagues instilled hearts with cardioplegic solution before establishment on an ex vivo, portable perfusion apparatus primed with the donor's own (deleukocyted) blood. In all cases, hearts resumed contractile activity and lactate metabolism was assessed for graft evaluation before the decision to proceed with transplantation was taken. Using a somewhat different approach, Large's group in the UK returned the heart to a beating state in situ to enable functional graft evaluation prior to ex vivo perfusion. For DCD hearts, graft evaluation is especially critical since no surgeon would take the risk of transplanting a heart without assessing its suitability. Indeed, as compared to traditional procedures in which graft evaluation and the decision to transplant occur before donor circulatory arrest, heart perfusion in DCD, whether it be regional in situ or ex vivo perfusion, provides the opportunity for graft evaluation after donor circulatory arrest and in a contracting mode. Also, with continuous perfusion on a portable system, assessment can be prolonged, for example in case of ambiguous results, and the decision to transplant can be delayed.

All the same, precise, evidence-based protocols for every step of the DCD heart transplantation process remain to be established. Indeed, conventional methods used with DBD hearts may not yield optimal outcomes as DCD hearts have undergone a period of ischemia prior to procurement and may thus be less tolerant than DBD hearts to additional exposure to damaging conditions. For example, given that DCD hearts are already arrested at the time of procurement and that strategies effective in limiting ischemic heart damage may only be allowed at reperfusion (procurement) for ethical reasons, conventional cardioplegic solutions may not be optimal for DCD hearts. Indeed, Thatte and colleagues have proposed a new cardioplegic solution developed specifically to limit damage to DCD heart grafts (12). Along similar lines, DCD may not be as tolerant to cold, static storage conditions as DBD hearts, since some degree of ischemic damage has already been initiated. Correspondingly, the two groups that recently reported DCD heart transplantations both employed perfusion storage, which, in addition to reducing ischemia during storage, also permits the monitoring of graft function and metabolism, as mentioned above.

Importantly, it may well be that evaluation reliability will be improved with the addition of other parameters in the future. We, and others, have shown that several relatively easily measurable parameters correlate very well with post-transplantation performance. For example, in pre-clinical ex vivo perfusion, Colah and colleagues demonstrated that left ventricular hemodynamics may be of potential value for graft evaluation (13); while our group reported that not only hemodynamics, but also biochemical parameters, such as oxygen consumption or markers of necrosis, provide information for the prediction of subsequent posttransplantation contractile recovery $(14,15)$.

The DCD approach for cardiac transplantation should be contemplated in light of not only new technological advances, such as ex vivo graft perfusion which may contribute to a better recovery, but also cardioprotective pharmacological and molecular strategies. It is true that varying ethical and legal limitations, such as the duration of the no-touch period, among countries are likely to influence the precise clinical strategies chosen (8). Strategies may involve the use of cardioplegic solutions and/or organ perfusion, as well as other post-conditioning therapies, whether biologic (cells, proteins, or genes), chemical (drugs), or physical (hypothermia).

The recent reports from Australia and the UK may one day be seen as critical events, marking fundamental changes in the way we view medicine. By transplanting hearts with potentially higher risks of post-operative dysfunction, both transplantation team and patient are asked to accept possibilities of higher post-operative morbidity and mortality, as well as reduced survival as compared to current standards. In other words, increasing the pool of donors with DCD may imply a "weakening" of reported transplantation results, although this "weakening" effect may already be ongoing, considering the increasing use of marginal donors (16), or the increasing donor age in Europe (17). On the other hand, this view concentrates only on patients who receive heart transplants and, as such, reflects performance of the heart transplantation procedure, but not the overall situation of the real problem, i.e., the entire group of transplantation candidates.

Obviously, many aspects must be thoroughly evaluated before DCD heart transplantation can become a routine procedure. Although these recent reports demonstrate the feasibility of this approach as a concrete and rapidly applicable possibility for helping more patients on the waiting list, it would be wrong to generalize without careful ethical, cultural, legal, and practical considerations. Nevertheless, there is an urgent need to find a solution for the rapidly growing number of patients who will never receive a DBD heart [in 2013, approximately 14.5 and $15.5 \%$ cardiac transplantation candidates died in the US and Europe, 
respectively (18)]. We definitely cannot continue to hope that large donation campaigns or political interventions will substantially influence organ availability. Also, we must accept that development of alternative therapies, such as artificial hearts, drugs, stem

\section{References}

1. Dhital K, Iyer A, Connellan M, Chew HC, Gao L, Doyle A, et al. Adult heart transplantation with distant procurement and ex-vivo preservation of donor hearts after circulatory death: a case series. Lancet (2015) 385(9987):2585-91. doi:10.1016/S0140-6736(15)60038-1

2. Smyth C. Doctors hail "dead" heart transplants. The Times (2015), 27th March.

3. Smyth C. "Dead" hearts give life to three transplant patients. The Times (2014), 25th October.

4. Dhanani S, Hornby L, Ward R, Shemie S. Variability in the determination of death after cardiac arrest: a review of guidelines and statements. J Intensive Care Med (2012) 27:238-52. doi:10.1177/0885066610396993

5. Gardiner D, Shemie S, Manara A, Opdam H. International perspective on the diagnosis of death. Br J Anaesth (2012) 108:i14-28. doi:10.1093/bja/aer397

6. Gries CJ, White DB, Truog RD, Dubois J, Cosio CC, Dhanani S, et al. An official American thoracic society/international society for heart and lung transplantation/society of critical care medicine/association of organ and procurement organizations/united network of organ sharing statement: ethical and policy considerations in organ donation after circulatory determination of death. Am J Respir Crit Care Med (2013) 188:103-9. doi:10.1164/rccm.201304-0714ST

7. Barnard CN. The operation. A human cardiac transplant: an interim report of a successful operation performed at Groote Schuur Hospital, Cape Town. S Afr Med J (1967) 41:1271-4.

8. Longnus SL, Mathys V, Dornbierer M, Dick F, Carrel TP, Tevaearai HT. Heart transplantation with donation after circulatory determination of death. Nat Rev Cardiol (2014) 11:354-63. doi:10.1038/nrcardio.2014.45

9. Kato G, Ishino K, Mohri M, Hisamochi K, Takagaki M, Sano S. Efficacy of an endothelin-A receptor antagonist in heart transplantation from asphyxiated canine non-heart-beating donors. Jpn J Thorac Cardiovasc Surg (2006) 54:511-5. doi:10.1007/s11748-006-0051-0

10. Osaki S, Ishino K, Kotani Y, Honjo O, Suezawa T, Kohmoto T, et al. Circulatory load during hypoxia impairs post-transplant myocardial functional recovery in donation after cardiac death. J Heart Lung Transplant (2009) 28:266-72. doi:10.1016/j.healun.2008.12.002

11. Boucek MM, Mashburn C, Dunn SM, Frizell R, Edwards L, Pietra B, et al. Pediatric heart transplantation after declaration of cardiocirculatory death. N Engl J Med (2008) 359:709-14. doi:10.1056/NEJMoa0800660 cells, or tissue engineering, remain long and cumbersome with no guarantee of success. Conversely, the development of a DCD heart transplantation program seems reasonable. Let us work together to make it happen.

12. Thatte HS, Rousou L, Hussaini BE, Lu XG, Treanor PR, Khuri SF. Development and evaluation of a novel solution, Somah, for the procurement and preservation of beating and nonbeating donor hearts for transplantation. Circulation (2009) 120:1704-13. doi:10.1161/CIRCULATIONAHA.108.808907

13. Colah S, Freed DH, Mundt P, Germscheid S, White P, Ali A, et al. Ex vivo perfusion of the swine heart as a method for pre-transplant assessment. Perfusion (2012) 27:408-13. doi:10.1177/0267659112449035

14. Dornbierer M, Stadelmann M, Sourdon J, Gahl B, Cook S, Carrel TP, et al. Early reperfusion hemodynamics predict recovery in rat hearts: a potential approach towards evaluating cardiac grafts from non-heart-beating donors. PLoS One (2012) 7:e43642. doi:10.1371/journal.pone.0043642

15. Sourdon J, Dornbierer M, Huber S, Gahl B, Carrel TP, Tevaearai HT, et al. Cardiac transplantation with hearts from donors after circulatory declaration of death: haemodynamic and biochemical parameters at procurement predict recovery following cardioplegic storage in a rat model. Eur J Cardiothorac Surg (2013) 44:e87-96. doi:10.1093/ejcts/ezt142

16. Coers BS, Ault ML. Con: the challenges of utilizing expanded-criteria donors for orthotopic heart transplantation. J Cardiothorac Vasc Anesth (2014) 28:1688-90. doi:10.1053/j.jvca.2014.06.009

17. Dipchand AI, Kirk R, Edwards LB, Kucheryavaya AY, Benden C, Christie JD, et al. The registry of the international society for heart and lung transplantation: sixteenth official pediatric heart transplantation report - 2013; focus theme: age. J Heart Lung Transplant (2013) 32:979-88. doi:10.1016/j.healun.2013.08.005

18. Council of Europe. International figures on donation and transplantation 2013. In: Matesanz R, editor. Newsletter Transplant. Madrid: Grupo Aula Médica (2014). p. 1-96.

Conflict of Interest Statement: The authors declare that the research was conducted in the absence of any commercial or financial relationships that could be construed as a potential conflict of interest.

Copyright (c) 2015 Tevaearai Stahel, Zuckermann, Carrel and Longnus. This is an open-access article distributed under the terms of the Creative Commons Attribution License (CC BY). The use, distribution or reproduction in other forums is permitted, provided the original author(s) or licensor are credited and that the original publication in this journal is cited, in accordance with accepted academic practice. No use, distribution or reproduction is permitted which does not comply with these terms. 